\title{
Aplicação de conceitos básicos em etologia na clínica médica veterinária felina
}

\section{Application of basic concepts in ethology in the feline veterinary medicine}

\section{Resumo}

O estudo da Etologia vem crescendo dentro da Medicina Veterinária e também pode-se observar um considerável aumento do número de gatos domésticos em nosso meio. Estes pontos ressaltam a importância de se estudar este animal de um ponto de vista etológico. O médico veterinário deve alertar o proprietário sobre aspectos comportamentais e discutir minuciosamente o que esperar de um animal de companhia, minimizando as chances de um conflito entre ambos, com um possível abandono. O conhecimento das características comportamentais, bem como do desenvolvimento do animal irá auxiliar a prevenção de problemas futuros.

\section{Summary}

The study of Ethology has grown in the Veterinary Medicine, and nowadays it can be observed a considerable increase in the number of domestic cats in our society. These points highlight the importance of studying this animal from an ethologic point of view. The professional should alert the owner about the behavioural aspects and thoroughly discuss what to expect from a companion animal, minimizing the possibilities of conflicts among them, which can lead to abandonment. The knowledge of the behavioural characteristics, as well as the development of the animal will help for the prevention of future problems. 
Caixa Postal 390 - Centro

14001-970 - Ribeirão Preto, SP - Brasil

gelsongenaro@hotmail.com

こ 1697778847

www.gelsongenaro.com.br

Palavras-chave

Etologia. Comportamento. Gato. Felino.

\section{Keywords}

Ethology. Behavior. Cat. Feline.

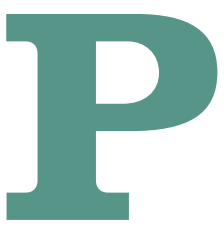

or incrível que possa parecer a maior causa de morte de gatos nos Estados Unidos é a eutanásia decorrente do excesso de animais em abrigos (ROCHLITZ, 2005). Muitos desses animais, em algum momento de suas vidas tiveram um proprietário, ou cuidador, então como esses animais terminaram seus dias dessa forma? Serão discutidas as razões de tal situação, particularmente da possível intervenção profissional médico veterinária nesse problema.

Nem todas as pessoas são apaixonadas pelos gatos, entretanto, o número de proprietários interessados nesta espécie cresce significativamente (TURNER; BATESON, 2000). Hoje há especialistas em áreas da Medicina Veterinária que tratam de enfermidades específicas do felino doméstico, existem também clínicas médicas veterinárias que atendem unicamente os indivíduos desta espécie. Portanto, é essencial que os estudantes de Medicina Veterinária tenham uma formação específica focada nas necessidades comportamentais do gato.

O estudo do comportamento animal, particularmente na disciplina de Etologia, vem crescendo dentro das áreas clínicas para uma grande variedade de espécies animais. Neste trabalho, centrado nos felinos domésticos, serão abordados dois aspectos importantes: o manejo e a Etologia. De início, a discussão será dirigida para as razões do aumento crescente do número de felinos em nosso meio (BRADSHAW, 2000; BROOM; FRASER, 2010). Nos dias atuais, há cada vez menos

1 Professor Doutor e Médico Veterinário (CRMV/SP - 6123), Dr. em Fisiologia pela FMRP-USP. Centro Universitária Barão de Mauá, 


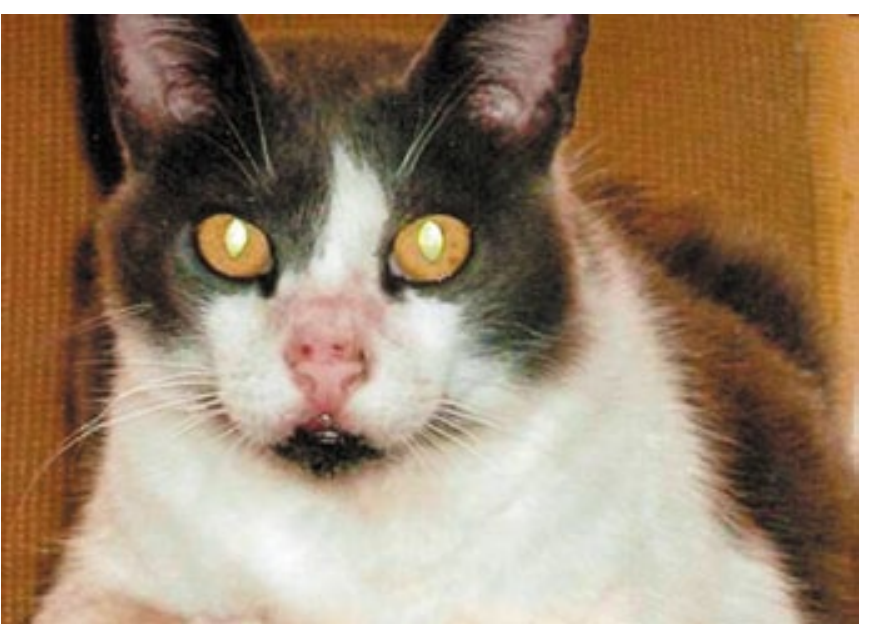

Figura 1 - Características felinas e cuidados necessários para o controle dos principais problemas comportamentais felinos

espaço e tempo disponíveis (Figura 1) e, dadas suas características comportamentais (Figura 2), esta espécie é capaz de se adaptar de maneira mais satisfatória que o cão, às circunstâncias que lhe são oferecidas. Porém, isso provavelmente também repercutirá em um aumento de situações de conflito, entre o proprietário e o animal, e também criará uma necessidade aguda do médico veterinário informar-se a respeito das condições indispensáveis que esta espécie, que até recentemente "viveu à sombra" do cão, necessita para se desenvolver e viver satisfatoriamente (GENARO, 2010). Neste ponto, são resgatados os conceitos fundamentais do bem-estar animal, ou seja, o estado do animal em questão, ao se defrontar com as condições domésticas que lhe são proporcionadas.

\section{Período Sensível e Enriquecimento Ambiental}

O período sensível, também denominado de período crítico, é a época da vida do animal em que eventos particulares são capazes de produzir efeitos importantes no seu comportamento, especialmente sobre a sua sociabilidade. As ligações sociais estabelecidas dentro desse período mais concentrado (no caso do gato doméstico, focado entre a segunda e a sétima/oitava semanas de vida) terão maiores chances de serem mantidas ao longo da vida do animal, com conseqüente maior impacto no seu comportamento quando adulto (TURNER; BATESON, 2000).

Evidentemente o aspecto genético do animal é relevante e as ligações e experiências vivenciadas durante o período sensível terão enorme repercussão na vida do indivíduo. As experiências dessa fase da vida do animal, deverão ser amplamente consideradas pelo clínico veterinário, pois as manipulações e experiências (favoráveis e desfavoráveis) servirão como um importante aprendizado para o animal e, a partir daí, o indivíduo terá facilidade ou dificuldade para os procedimentos futuros que o envolverem. Deve-se estar muito atento a esse período (Figura 3) e, na medida do possível, fazer o uso favorável dessas experiências, ou pelo menos, minimizar os efeitos negativos gerados por situações inevitáveis (manipulações dolorosas, contenções, transporte, etc.).

Tendo passado o período sensível (ou mesmo quando o gato é adquirido após este período - o que frequentemente ocorre), é essencial a continuidade das boas interações e das experiências positivas, já que o felino continua a aprender, ainda que com menos flexibilidade e mais receios, se comparado ao período sensível.

Outra característica a qual se deve estar atento é que o animal denominado de gato doméstico é uma espécie de 'pool'. Um verdadeiro aglomerado de perfis comportamentais, que vai desde um animal dócil e altamente dependente de seu proprietário até aquele mais esquivo, e que se mantém à distância perpetuamente (GENARO; COLLUCCI, 2009). Aquele mais dócil pode mesmo nunca ter visto outro indivíduo de sua espécie, além de sua mãe e irmãos, ou nunca ter pisado em solo, vivendo em apartamentos por toda sua existência, contrapondose a aqueles indivíduos denominados ferais, que foram, por várias gerações, mantidos distantes de um convívio próximo às pessoas, caçando ou alimentando-se de sobras encontradas.

Muitos desses animais, não apenas os denominados de ferais, mas também os que vivem nos quintais, autodeterminam seus acasalamentos, independentemente, vivendo uma situação muito próxima aos animais silvestres, sem maiores interferências - em seus acasalamentos - advindas do convívio com humanos. Logo, deve-se considerar com mais cuidado se esse animal vive realmente uma vida doméstica.

Contudo, deve-se de ter em mente a possibilidade de variações no perfil dos animais, já que além dos aspectos acima relacionados, também devem ser considerados: o contato com a mãe, o temperamento dos pais, a experiência com seus possíveis irmãos de ninhada, todos em conjunto, interferindo no perfil 'final' do indivíduo.

Existem, então, duas situações às quais o profissional deve estar atento, pois os problemas e situações originados nos animais mantidos em restrição de deslocamento (sendo denominados de domiciliados) são extremamente diferentes daquelas de animais não domiciliados. Portanto, o proprietário deve ser informado dessas questões. Fundamentalmente esses animais são os mesmos, diferindo, apenas, no relativo a situação a que foram submetidos. E é aqui que se percebe a relevância do Período Sensível. Um exemplo consideravelmente importante e 

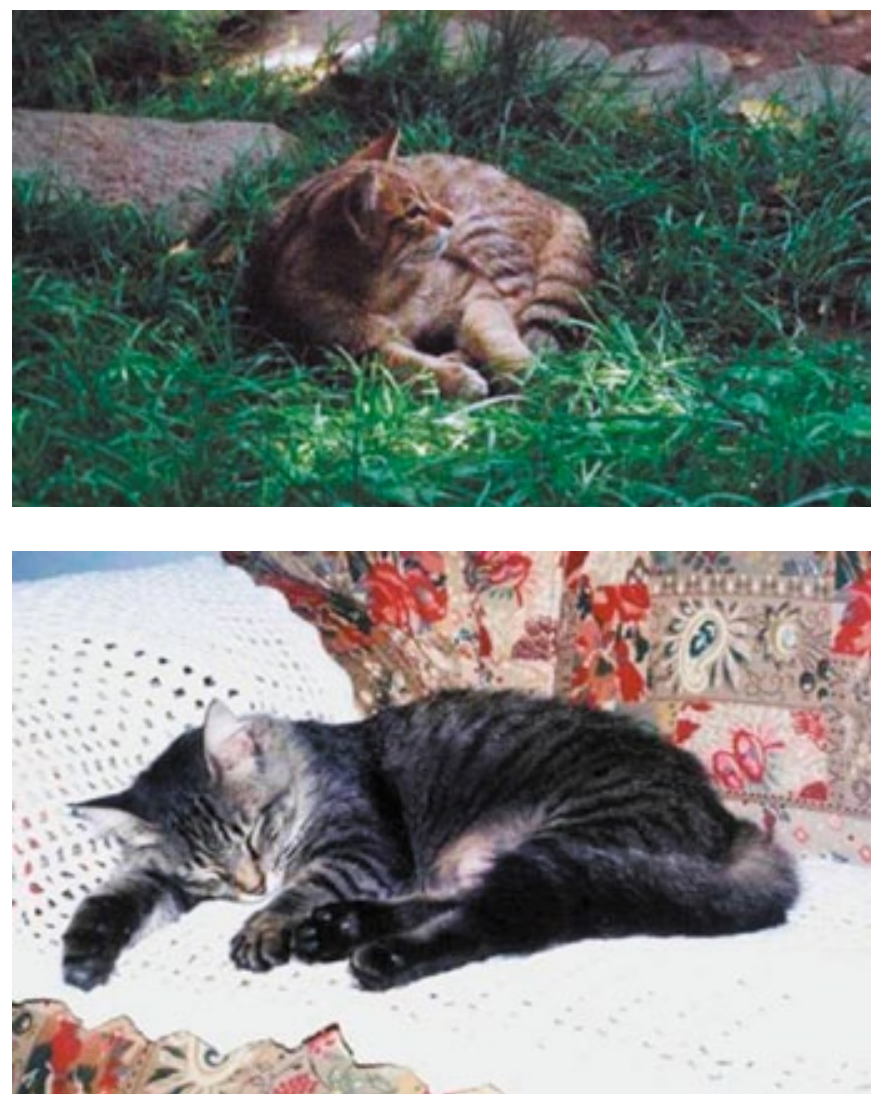

que pode ser observado no cotidiano da clínica médica veterinária: a falta de manipulação do filhote, especialmente entre a segunda e a sétima/oitava semanas de vida culmina, normalmente, num indivíduo adulto irascível, intolerante às manipulações necessárias da Clínica.

Portanto o ato, a princípio, irrelevante de abandonar uma mãe com sua ninhada - ou somente os filhotes, ou ainda, qualquer variação dessa forma de descaso é criar condições para que esses animais se tornem o que se denomina de ferais, ou asselvajados, com todas as consequências sanitárias advindas desse descaso, tornando-se mais difícil (senão impossível), no futuro, o seu manuseio, seja por parte do médico veterinário ou do cuidador.

Alguns indicadores comportamentais relevantes de estresse devem ser considerados: gatos ferais quando mantidos reclusos não se alimentam, não realizam a auto limpeza, e evitam, ao máximo, o ato de defecar, sinais inequívocos de inibição comportamental, situação muito clara de um estresse extremado. São comuns as oportunidades em que esses animais (ferais ou assemelhados) são submetidos a um convívio forçado, por exemplo, em centros de controle de zoonoses, abrigos, ou mesmo nas clínicas quando são mantidos para medicação. Essa situação também ocorre na casa do proprietário quando

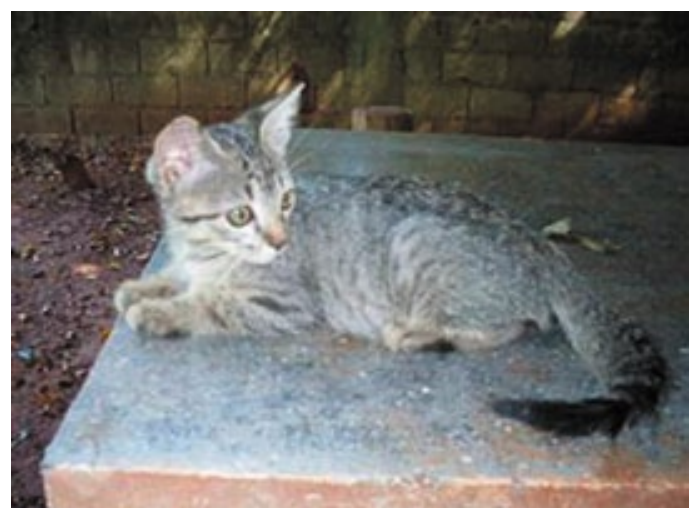

Figuras 2 - O período inicial de desenvolvimento do gato doméstico é determinante para seu perfil comportamental na vida adulta

um novo indivíduo é introduzido dentro de um plantel já estabelecido (socialmente). Logo, deve-se estar atento às características do animal e, quando existirem indivíduos com essas peculiaridades, deve-se oferecer as condições mínimas exigidas para o animal, por exemplo, uma acomodação em separado, ou acobertada, para permitir que o animal sinta-se minimamente confortável, além de ser facilitado o trabalho dos profissionais envolvidos (MACHADO; GENARO, 2010).

$\mathrm{O}$ gato responde, normalmente, com inatividade quando mantido em situações estressantes. Portanto, alterações de comportamento são frequentemente os primeiros indicadores de empobrecimentos do seu Bem Estar, ou também de processos patológicos em curso (ROCHLITZ, 2005).

Recomenda-se que seja disponibilizado ao animal uma separação considerável entre as áreas de: alimentação, descanso e eliminação (de fezes e urina), e, quando há vários animais em grupos, deve-se oferecer mais uma opção de área, que é a de isolamento para algum indivíduo que deseje manter-se afastado dos demais. $\mathrm{Na}$ possibilidade do animal não contar com essas opções o mais comum é que passe a limitar suas atividades, como anteriormente descrito, criando condições para que ocorram processos patológicos (diversos). 

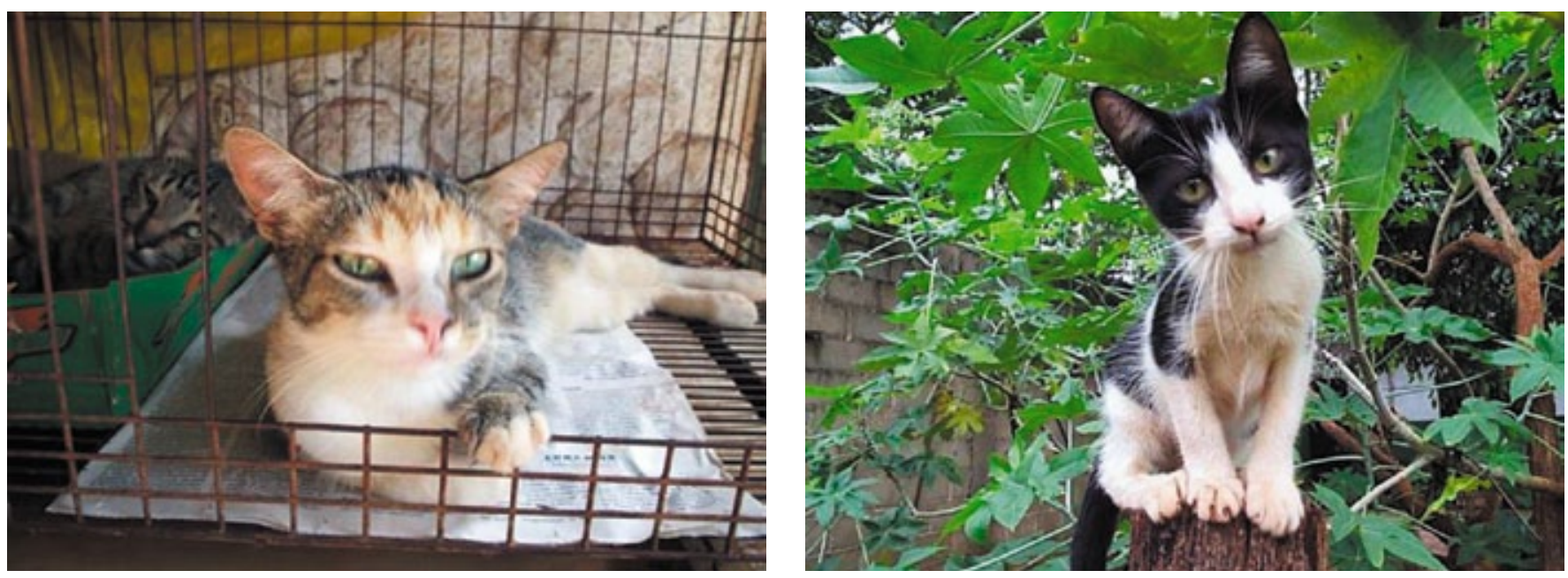

Figuras 3 e 4 - Representação esquemática para o bem-estar felino, relacionando a limitação ambiental e o comportamento exploratório

Outro ponto a que se deve estar atento, como profissionais, é a qualidade da área disponibilizada ao animal. O gato, como um excelente escalador, apresenta necessidades específicas quanto a esse aspecto, portanto empoleirar-se em locais seguros e isolados, sempre acima do piso, é uma necessidade muito importante que precisa ser atendida (MACHADO; GENARO, 2010; ROCHLITZ, 2005).

Para um animal com os sentidos tão desenvolvidos, como são os mamíferos na sua maioria, é fundamental um aporte satisfatório de estímulos. Não se deve esquecer que este animal é um caçador muito eficiente, logo mantê-lo entretido é um desafio contínuo (BRADSHAW, 2000). Existem diversas opções que poderão ser levadas em conta, e o profissional deverá considerar: a segurança do animal, e dos demais envolvidos (cuidadores, outros animais, etc.), além dos custos e possibilidades de execução da proposta. Essa é uma área específica da Etologia, o enriquecimento ambiental, que irá possibilitar a manifestação do comportamento exploratório do animal (DANTAS-DIVERS et al., 201; 1MACHADO; GENARO, 2010); que pode ser definida como a atividade promovida por um estímulo, normalmente novo, e que consiste em atos e posturas, que levam à obtenção de informações sobre um objeto, ou ambiente, não familiar. Deve-se, entretanto, considerar também a dependência do temperamento do indivíduo, bem como, da situação a que está submetido, que poderá desencadear comportamentos típicos da espécie (por exemplo: que o auxiliariam em situações adversas, escondendo-se).

O enriquecimento ambiental (Figura 4) visa criar um ambiente mais propício e estimulante para o indivíduo, permitindo que o animal expresse suas manifestações corriqueiras, facilitando a sua adaptação a um ambiente desafiador, mantendo-o ocupado, por meio das situações propostas e minimizando o seu sofrimento. A adaptação de diferentes propostas é sempre possível, desde que o proprietário esteja consciente da necessidade de adequar $o$ meio ambiente às necessidades de seu animal. $O$ favorecimento da adaptação do animal aos desafios impostos pelo ambiente, proporcionará uma condição de bem-estar privilegiada que atenderá às requisições do indivíduo, que, são muito próximas as dos seus familiares silvestres.

\section{Considerações Finais}

O profissional deve alertar o proprietário de felídeos sobre os aspectos comportamentais desses animais e discutir minuciosamente sobre o que ele espera de um animal de companhia, minimizando as chances de um conflito entre ambos, com um possível abandono. Muitas reclamações apresentadas por proprietários são manifestações corriqueiras de um animal mantido em condições inadequadas, ou mesmo consideradas normais para um gato, em residências. Portanto, o proprietário deve ter a exata medida do que terá pela frente ao adquirir um exemplar dessa espécie animal.

O conhecimento das características comportamentais, bem como do desenvolvimento e da evolução temporal do animal que se pretende adquirir poderá auxiliar na prevenção de problemas comportamentais, intervindo-se assim o mais precocemente possível, ou mesmo corrigindo-se transtornos comportamentais adquirido, caso as opções anteriores não tenham sido efetivas.

Animais mantidos em residências, sem acesso à rua, possuem maior longevidade, fruto do isolamento sanitário, ou da prevenção de incidentes comuns (acidentes, conflitos, etc.). Entretanto, o empobrecimento advindo desse isolamento pode tornar-se fonte de alterações, inicialmente comportamentais, e mais tarde com significativas manifestações clínicas problemáticas. Um 
exemplo: o isolamento social (enfatizado neste texto), que é fruto de um proprietário que possui apenas um único animal mantido nessa condição desde a infância até a vida adulta, poderá determinar que este indivíduo não se aproxime de outro para o acasalamento ou mesmo se tiver que ser mantido próximo a outros animais. Com essas informações básicas, tanto o profissional como o proprietário poderão minimizar as chances de ocorrerem problemas e conflitos ao longo da vida do animal.

\section{Referências}

BRADSHAW, J. W. S. The behaviour of the domestic cat. Wallingford: CABI Publishing 2000. p. 219.

BROOM, D. M.; FRASER, A. F. Comportamento e bem estar de animais domésticos. 4 ed. Barueri: Manole, 2010. p. 438.

DANTAS-DIVERS, L. M. S.; CROWELL-DAVIS, S. L.; ALFORD, K.; GENARO, G.; D'ALMEIDA, J. M.; PAIXÃO, R. L. Agonistic behavior and environmental Enrichmentof cats communally housed in a shelter. JAVMA, v. 239, n. 6, p. 796-802, 2011

GENARO, G.; COLLUCCI, E. Posse responsável de animais de companhia. Ciência Hoje v. 44, n. 260 , p. $68-69,2009$.

GENARO, G. Gato doméstico: futuro desafio para controle da raiva em áreas urbanas? Pesquisa Veterinária Brasileira, v. 30, n. 2, p.186-189, 2010.

MACHADO, J. C.; GENARO, G. Comportamento exploratório em gatos domésticos (Felis silvestris catus Linnaeus, 1758): uma revisão. Archives of Veterinary Science, v. 15, p 107-117, 2010

ROCHLITZ, I. The welfare of cats. Dordrecht, The Netherlands: Springer, 2005. $282 \mathrm{p}$

TURNER, D. C.; BATESON, P. The domestic cat - The Biology of its behaviour. Cambridge: Cambridge Univeristy Press, 2000. p. 244.

Agradecimentos:

Ao Dr. Alexandre Jacques Louis Develey pelo estímulo na redação deste manuscrito e também ao revisor anônimo que contribuiu substancialmente na preparação deste. 